\title{
Association of Infant and Child Health Characteristics With the Hazard of Any Medical Condition or Disability in Australian Children
}

Kabir Ahmad ( $\nabla$ kabir.ahmad@usq.edu.au )

University of Southern Queensland https://orcid.org/0000-0003-0208-5725

Syed Afroz Keramat

Khulna University

Nusrat Jahan Sathi

Khulna University

Enamul Kabir

University of Southern Queensland Faculty of Sciences: University of Southern Queensland Faculty of Health Engineering and Sciences

\section{Rasheda Khanam}

University of Southern Queensland Faculty of Business: University of Southern Queensland Faculty of Business Education Law and Arts

\section{Research Article}

Keywords: medical condition, disability, hazard rate, birthweight, obesity, intensive care unit

Posted Date: February 14th, 2022

DOI: https://doi.org/10.21203/rs.3.rs-1254551/v1

License: @ (i) This work is licensed under a Creative Commons Attribution 4.0 International License. Read Full License 


\section{Abstract}

Background: The incidence of any medical condition (e.g., sight, hearing, and speech problems, blackouts, chronic pain etc.) or disability (e.g., limited use of arms or fingers, legs, and feet, or other physical long-term health condition limiting everyday activities etc.) have been increasing among Australian children in recent decades.

Objectives: This study assessed whether infant or child health characteristics might be predictors of subsequent medical conditions or disabilities in children in the first 15 years of life.

Methods: Using time to event data of 5107 children, obtained from the Birth cohort of the Longitudinal Study of Australian Children, the study estimated the incidence of any medical condition or disability using the survival analysis technique. This study followed up the children from birth to 14 or 15 years of age (2004 - 2018) and assessed the association of infant and child health characteristics (birthweight, gestational age, use of intensive care unit or ventilator during their neonatal age and obesity) with hazard of any medical condition or disability using the random effect parametric survival regression model. The infant characteristics were measured in the Wave 1 while the children were aged 0/1 year and obesity characteristics were measured longitudinally over all the waves up to $14 / 15$ years of age.

Results: The hazard rate of any medical condition or disability for all participants was 26.13 per 1000 person-years among children in Australia. This hazard incidence was higher among low birthweight (39.07) and obese (34.37) children and among those who had received after-birth ventilation or intensive care unit emergency services (36.87). The parametric panel regression model also suggests that children with low birthweight were 1.43 times (Hazard Ratio: 1.43, 95\% Confidence Interval: 1.05 - 1.94) more likely to have any medical condition or disability than children with normal birthweight. The time to event analyses also revealed that being recipient of after-birth emergencies (HR: 1.47, 95\% Cl: 1.23 - 1.75), being male children (HR: 1.30, 95\% Cl: 1.14 - 1.48) or being obese (HR: 1.38, 95\% Cl: 1.07 - 1.79) significantly increased the likelihood of the incidence of a medical condition or disability among children. The regression model was adjusted for region of residence, language spoken at home, indigenous status, whether the study child has both parents, mothers age at birth and education of mothers.

Conclusions: This study predicts the risk factors of any medical condition or disability among Australian children. The study findings suggest that infants with low birth weight, hospital emergency service use and children with obesity would benefit from additional health care monitoring to minimize the risk of any medical condition or disability.

\section{Background}

Medical conditions or disabilities generate a disease burden for children worldwide. The term 'medical condition or disability' refers to any disabilities and related medical conditions of adults and children, for example, sight, hearing, and speech problems, blackouts, chronic pain, nervousness, head injuries, difficulty in breathing, learning difficulties, limited use of arms or fingers, legs, and feet, gripping problem, or other physical long-term health conditions [1, 2]. The Global Burden of Disease study in 2004 estimated that a total of $5.1 \%$ (93 million) children aged 14 or under lived with moderate or severe disability, amongst $0.7 \%$ ( 13 million) survived with severe medical condition [3]. In addition, approximately 150 million children aged 18 years or under had medical condition or disability, most of whom live with the reality of exclusion in the world [4]. A similar picture has been observed in Australia. In 2018, nearly $7.7 \%$ (357,500) of children under 15 years had experienced any medical condition or disability, of which $4.5 \%$ and $1.6 \%$ had severe and moderate/mild conditions, respectively [5]. In addition, the proportion of children with disability has been increased from $6.9 \%(295,900)$ in 2012 [5].

The available literature shows that children's health state, such as having any medical condition or disability, in childhood depends on the health characteristics of the mother and their offspring during pregnancy and childbirth [6-11]. Low birth weight and shorter gestation period/preterm birth are significantly associated with increased risk of any medical condition among children $[7,9,10]$. Past studies in the US and China revealed that gender, a biological factor, substantially impacted disability $[9,11]$. In addition, a systematic review confirmed that the likelihood of being overweight and obese increased the risk of acquiring disabilities in children by 1.54 and 1.80 times, respectively [8]. Two earlier studies had found that perinatal factors, such as low birth weight and premature birth, were associated with a higher likelihood of disability acquisition [12, 13]. One of the main limitations of the existing literature is that most of the previous studies have been focused on identifying the risk factors of disability among adults and older 
people [14, 15]; however, a small number of the available child health focused studies are either cross-sectional or not of contemporary birth cohorts $[7,9,10]$. Another limitation is there is no longitudinal time to event studies or survival analyses in the Australian setting to identify the risk factors of medical condition or disability among children.

To overcome the limitations of current literature, the present study aims to assess the association between infant health-related characteristics with any medical condition or disability acquisition in Australian children. This cohort study will reveal knowledge, as an early warning for the children before they enter into their adulthood, about the risk factors of the incidence of any medical condition or disability using 15-year of follow-up data from the nationally representative Australian birth cohort.

\section{Methods}

\section{Data source and sample selection}

The data came from the birth cohort of the Longitudinal Study of Australian Children (LSAC), a representative household survey of Australian children that began in 2004 and biennially collects information on the health (physical and socio-emotional) and development of Australian children based on the context of the bio-ecological framework of human development [16]. For the current analysis, we used Wave 1 as the baseline $(n=5107)$ and followed the development of the children up to Wave $8(n=3127)$ which resulted in 51009 person-year data for the survival analysis. As this was a birth cohort, we considered all the children of the baseline survey as being independent of any medical condition or disability. Demographic characteristics, any medical condition or disability and other health related status for children were all identified using the data dictionary of the LSAC study.

\section{Outcome variable}

The diagnostic of having any medical condition or disability was acquired by the LSAC study from the caregivers of the children at the survey of each wave, conducted between 2004 and 2018. Any medical condition or disability includes the incidence of longterm medical conditions or disabilities or disabilities limiting everyday activities. Long-term medical conditions or disabilities include sight problems, hearing problems, speech problems, blackouts, difficulty learning, limited use of arms or fingers, difficulty gripping, limited use of legs and feet, other physical condition, or other disfigurement which lasted around 12 months. Disabilities limiting every day activities includes difficulty breathing, chronic pain, nervous condition, head injuries, other long-term conditions, or other treated conditions. A dichotomous variable was generated and coded with the value 1 for having any of these medical conditions or disabilities and 0 for not having any of these diseases at each wave's survey. Afterwards, time to event data were generated from the longitudinal data of all waves using the survival function to estimate the incidence rate of any health condition or disability.

\section{Independent variables}

The following variables were considered as the independent variables in this study: birthweight (low: <2500 gram, normal: 2500 4000 gram, high: $>4000$ gram), gestational age (early: $<37$ weeks, on-time: $37-41$ weeks, late: $>41$ weeks), obesity status (underweight: <=5th percentile, normal: 6th to 84th percentile, overweight: 85th to 94th percentile, obese: $>=95$ th percentile) of the children and after birth emergency service use (yes: ventilation or intensive care unit service use, no: none of these services use). The options of the responses of the selected variables were available in the LSAC data as mentioned in the brackets of the variables. Birthweight, gestational age and emergency service use were measured in the Wave 1 while the children were aged 0/1 year. Obesity status of the children were measured longitudinally over all the waves from the children's birth to 14/15 years of age.

\section{Control variables}

This study considered the following socio-demographic covariates as confounding variables: (i) age of the children (14 to 19 years), (ii) gender of the children (male or female), (iii) whether English is spoken at home (yes or no), (iv) whether children have both parents (both parents, single parent), (v) indigenous status (yes or no), (vi) education of mother (year 12 or less, certificate, graduate degree/diploma, postgraduate), (vii) remoteness of the family residence (highly accessible, accessible/moderately accessible, or remote/very remote).

\section{Statistical Analyses}


Descriptive statistics were used to summarize characteristics of children and mothers. The occurrence of any health condition or disability was estimated from 51009 person-year survival data which was derived from 5107 children followed up until 15 years age, using the Kaplan-Meier method of survival analysis. The panel data parametric hazard model was used to estimate the hazard ratio of developing any medical condition or disability and the accumulation of incidence rate of the hazard among the participants. Techniques of panel survival analysis were employed to assess the impact of independent variables on the occurrence of any health condition or disability. We defined the onset of having any health condition or disability as the point of time from which a child was identified having a health condition or disability by the caregiver in the follow-up surveys; and calculated the onset of time by calculating the age of the children during the reporting time. A person was denoted as being censored if they were dropped out from any point of the follow-up survey. Panel regression hazard model assumptions were checked, and the multivariate model was fit adjusting for prespecified infant and maternal health related confounders. A predictor was considered statistically significant if the respective $p$-value of a particular exposure was less than or equal to 0.05 in the multivariate regression analyses. Analyses were performed using Stata version 16 (Stata Inc.).

\section{Results}

\section{Study participants}

Table 1 shows the participants' baseline characteristics in Wave 1, and the representation of the baseline characteristics in the subsequent follow-ups up to Wave 8 . Among the 5107 participants at baseline, $12.81 \%$ children had birthweight over 4000 grams, $5.68 \%$ of children's weight was over 95 percentiles, $6.57 \%$ children had premature birth and $16.86 \%$ children needed ventilation/intensive care unit support after their birth. During the 15-year follow-up period, 1980 participants dropped out or were lost to follow-up. Among these dropouts, there were no significant differences in terms of characteristics of gender, birthweight, gestational age and afterbirth emergency. In Wave 8, a total of 3127 children participated; among them $51.36 \%$ were male participants, $9.35 \%$ children were overweight, $6.36 \%$ children were obese, $5.86 \%$ children had a premature birth and $16.37 \%$ children required ventilation/intensive care unit intervention after birth. The prevalence of any medical condition or disability varied longitudinally among the children, ranged in between $4.04-9.44 \%$ and reached to its peak during Wave $3(9.44 \%)$ and Wave 4 (8.44\%), while the children were 4 to 7 years old (see Figure 1). 
Table 1

Baseline Characteristics of the first wave and the subsequent follow-ups, LSAC study, $2004-2018$

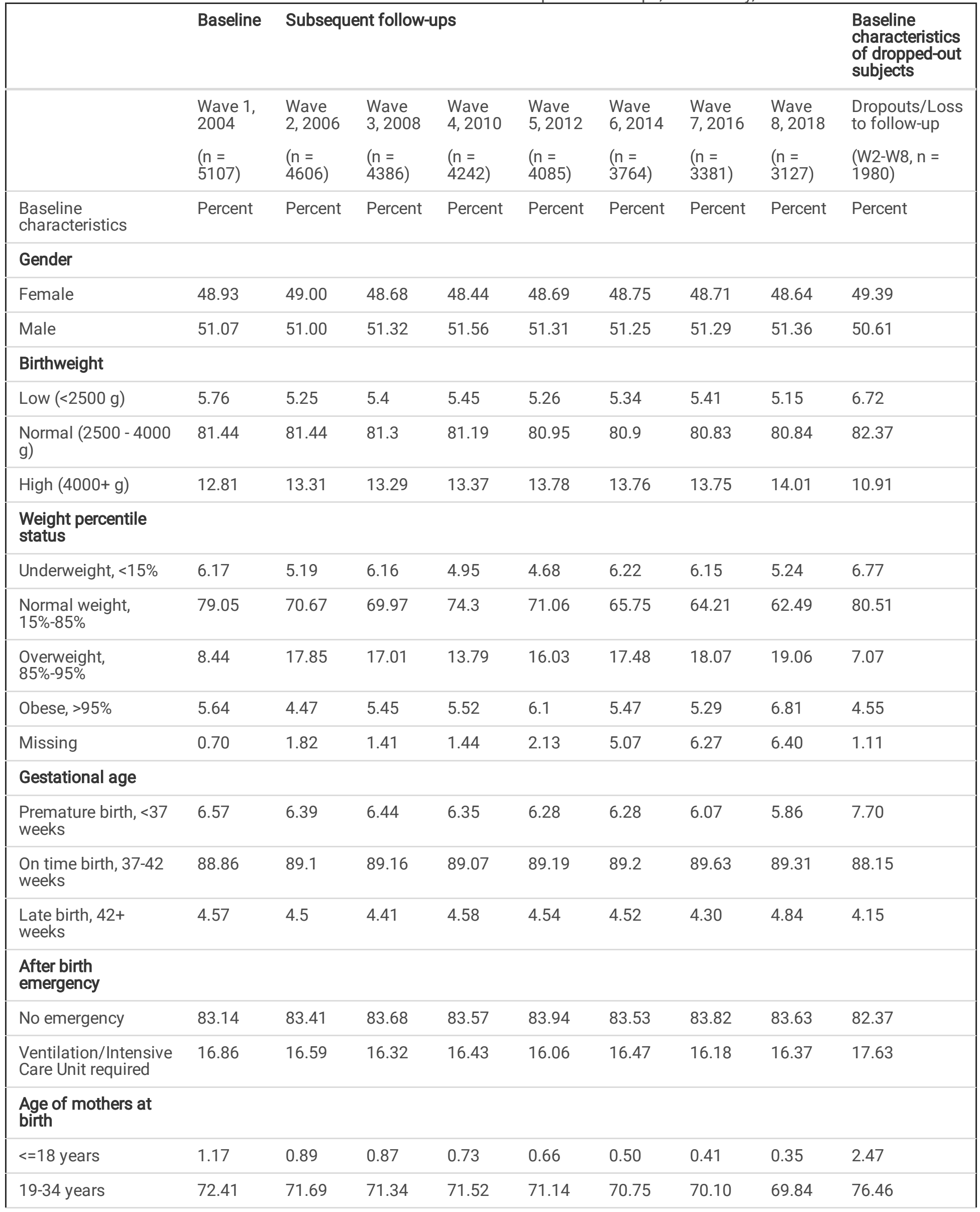




\begin{tabular}{|c|c|c|c|c|c|c|c|c|c|}
\hline \multirow[b]{2}{*}{$>=35$ years } & \multirow{2}{*}{$\begin{array}{l}\text { Baseline } \\
26.41\end{array}$} & \multicolumn{7}{|c|}{ Subsequent follow-ups } & \multirow{2}{*}{$\begin{array}{l}\text { Baseline } \\
\text { characteristics } \\
\text { of dropped-out } \\
\text { subjects }\end{array}$} \\
\hline & & 27.42 & 27.79 & 27.75 & 28.2 & 28.75 & 29.49 & 29.80 & \\
\hline \multicolumn{10}{|l|}{ Have both parents } \\
\hline Yes & 90.54 & 89.58 & 88.42 & 87.08 & 85.78 & 84.56 & 82.17 & 81.74 & 84.09 \\
\hline \multicolumn{10}{|l|}{ Maternal education } \\
\hline $\begin{array}{l}<12 \text { years of } \\
\text { education }\end{array}$ & 31.72 & 30.37 & 29.72 & 29.64 & 29.14 & 27.82 & 26.74 & 26.12 & 40.60 \\
\hline $\begin{array}{l}12 \text { years of } \\
\text { education }\end{array}$ & 25.60 & 25.39 & 25.11 & 24.64 & 24.48 & 24.39 & 23.84 & 23.82 & 28.43 \\
\hline Graduate/Diploma & 35.59 & 36.72 & 37.59 & 38.12 & 38.59 & 39.73 & 40.85 & 41.20 & 26.71 \\
\hline University Masters & 7.08 & 7.52 & 7.58 & 7.6 & 7.79 & 8.06 & 8.56 & 4.87 & 4.26 \\
\hline \multicolumn{10}{|l|}{$\begin{array}{l}\text { Remoteness of } \\
\text { residence }\end{array}$} \\
\hline Highly accessible & 55.46 & 55.63 & 55.29 & 55.15 & 54.64 & 55.03 & 54.67 & 55.19 & 55.89 \\
\hline Accessible & 23.53 & 23.57 & 23.82 & 23.69 & 24.36 & 23.87 & 24.16 & 23.88 & 22.98 \\
\hline $\begin{array}{l}\text { Moderately } \\
\text { accessible }\end{array}$ & 16.64 & 16.49 & 16.63 & 16.97 & 16.79 & 16.97 & 17.02 & 16.58 & 16.73 \\
\hline Remote/very remote & 4.38 & 4.30 & 4.26 & 4.19 & 4.21 & 4.13 & 4.16 & 4.36 & 4.4 \\
\hline
\end{tabular}

\section{Hazard rate of any medical condition or disability}

The hazard rate of any medical condition or disability (at least one) for all participants was 26.13 per 1000 person-years in children followed-up from age 0 to 15 years in Australia, in the period between 2004 and 2018. The hazard rate was higher for those who had low birth weight (<2500 gram) in 2004 compared with normal birthweight children (39.07 and 24.89/1000 person-years, respectively). This pattern was also observed among the underweight and obese children; among them hazard rate was around 1.5 times higher compared with normal weight children (Table 2). Table 2 also presents the incidence rate (of hazards) by gestational age and after-birth emergency service categories. Children who were born early and received afterbirth ventilation or intensive care unit (ICU) services had higher hazard rate (around 1.5 times) relative to those who born on time and did not receive any emergency services, respectively. 
Table 2

Hazard rate of any medical condition or disability in the living per 1000 person-years in children followed-up from age 0 to 15 years in Australia, according to birthweight, gestational age and obesity, 2004-2018

\begin{tabular}{|c|c|c|}
\hline & \multicolumn{2}{|l|}{ Total } \\
\hline & Hazard Rate & $95 \% \mathrm{Cl}$ \\
\hline All participants & 26.13 & $24.77-27.57$ \\
\hline \multicolumn{3}{|l|}{ Birth weight } \\
\hline $\operatorname{Low}(<2500 \mathrm{~g})$ & 39.07 & $32.15-47.49$ \\
\hline Normal $(2500-4000 \mathrm{~g})$ & 24.89 & $23.43-26.45$ \\
\hline $\operatorname{High}(>4000 \mathrm{~g})$ & 28.89 & $25.08-33.28$ \\
\hline \multicolumn{3}{|l|}{ Gestational age } \\
\hline Early (<37 weeks) & 35.16 & $29.92-44.38$ \\
\hline On-time (37-41 weeks) & 25.58 & 26.13-29.33 \\
\hline Late (>41 weeks) & 25.24 & 21.49-35.65 \\
\hline \multicolumn{3}{|l|}{ Obesity } \\
\hline Underweight (<=5th Percentile) & 36.42 & $29.99-44.23$ \\
\hline Normal (6th to 84th Percentile) & 24.82 & $23.24-26.50$ \\
\hline Overweight (85th to 94th Percentile) & 26.23 & 22.94-29.99 \\
\hline Obese (>=95th Percentile) & 34.36 & $28.05-42.11$ \\
\hline \multicolumn{3}{|l|}{ After birth emergency } \\
\hline No & 24.20 & 22.78-25.71 \\
\hline Yes (Ventilation/ICU) & 36.87 & $32.85-41.40$ \\
\hline \multicolumn{3}{|c|}{$\begin{array}{l}\text { Note: Any medical condition/disability includes the incidence of long-term medical condition/disability and disability limiting } \\
\text { everyday activities; Long-term medical condition/disability includes sight problems, hearing problems, speech problems, } \\
\text { blackouts, difficulty learning, limited use of arms or fingers, difficulty gripping, limited use of legs and feet, other physical } \\
\text { condition, or other disfigurement which lasted around } 12 \text { months; Disability limiting every day activities includes difficulty } \\
\text { breathing, chronic pain, nervous condition, head injury, other long-term condition, or other treated condition }\end{array}$} \\
\hline
\end{tabular}

Figure 2 displays random effects Weibull proportional hazard regression curve on hazard ratio over time by birthweight, obesity status, gestational age and after birth emergency of the children. It is evident from the graph that hazard ratio for all risk factors increases over time. The increasing trend was higher for children with low birthweight, obese children and those who received ventilation or ICU services compared to other reference categories shown in Figure 2. Figure 3 shows the cumulative hazard ratio and Figure 4 shows the survival rate over time for the same risk factors shown in Figure 2. Cumulative hazard ratio curves of Figure 3 have the similar trends of hazard ratio curves shown in Figure 2, revealing with a steeper increase while follow-up time advances. In Figure 4, diminishing trends of survival are evident with lower survival rates for low birthweight, obese and emergency service recipient children compared to the children of reference categories.

\section{Regression model results}

Table 3 presents the results of the panel regression model for the hazards of any medical condition or disability among the children based on survival analysis. In the adjusted regression model, low birthweight and obesity were predictive of medical condition or disability, presenting a risk of 1.43 times and 1.38 times higher hazard than those with normal birthweight and normal weight, respectively. However, high birthweight and overweight were not significant to predict the medical condition or disability of the 
children. Among the other independent factors, male children and children who received afterbirth emergency services were strongly associated with higher risk of any medical condition or disability with hazard ratio of 1.47 and 1.30 respectively $(p-v a l u e<0.001)$.

Table 3

Panel data parametric survival model for any medical condition/disability health hazard among Australian children, 2004-2018

\begin{tabular}{|c|c|c|c|}
\hline & \multicolumn{3}{|c|}{ Regression Model } \\
\hline & Hazard ratio & p-value & $95 \% \mathrm{Cl}$ \\
\hline \multicolumn{4}{|l|}{ Birthweight } \\
\hline \multicolumn{4}{|l|}{2500 - 4000 gram (ref.) } \\
\hline$<2500$ gram & 1.43 & 0.023 & $1.05-1.94$ \\
\hline $4000+$ gram & 1.22 & 0.036 & $1.01-1.46$ \\
\hline \multicolumn{4}{|l|}{ Obesity of children } \\
\hline \multicolumn{4}{|l|}{ Normal weight (ref.) } \\
\hline Underweight & 1.23 & 0.117 & $0.95-1.61$ \\
\hline Overweight & 0.97 & 0.766 & $0.81-1.17$ \\
\hline Obese & 1.38 & 0.013 & $1.07-1.79$ \\
\hline \multicolumn{4}{|l|}{ Gestational Age } \\
\hline \multicolumn{4}{|l|}{ Matured birth, 37-42 weeks(ref.) } \\
\hline Early birth, $<37$ weeks & 0.83 & 0.190 & $0.60-1.11$ \\
\hline Late birth, $42+$ weeks & 0.76 & 0.132 & $0.53-1.09$ \\
\hline \multicolumn{4}{|l|}{ After birth emergency } \\
\hline \multicolumn{4}{|l|}{ No emergency (ref.) } \\
\hline Ventilation/Intensive Care Unit required & 1.47 & 0.000 & $1.23-1.75$ \\
\hline \multicolumn{4}{|l|}{ Gender of the child } \\
\hline \multicolumn{4}{|l|}{ Female (ref.) } \\
\hline Male & 1.30 & 0.000 & $1.14-1.48$ \\
\hline
\end{tabular}

\section{Discussion}

The present study focused on Australia and determined the incidence of children with any medical condition or disability based on time to event analysis and investigated its association with child health-related characteristics. The estimated incidence of any medical condition or disability was 26.13 per 1000 person-year among Australian children. The study also found that the hazard rate was higher for children born with low weight or receiving after-birth emergency services.

The main point revealed from the study is that children with low birthweight have higher hazards of developing any medical condition or disability compared to the children who have healthy birthweight. A follow-up study conducted in the USA aligns with our study findings that low birthweight increases children's risk of any medical condition [17]. In addition, similar results have been observed in some previous studies $[7,9,10]$. However, the results contradict an earlier study that revealed no significant association between low birthweight and subsequent disorder in children [18]. One possible reason could be that low birthweight generates complications for children's health because it is hard to gain weight and fight infectious diseases [19]. Immaturities in different organs, lower immunity, weakness, and low body fat are other plausible reasons for disease burden due to low birthweight [19]. 
The hazard of experiencing any medical condition or disability is higher for obese children compared to children who have normal weight. Our findings have added further insight into the existing literature which is consistent with this result [8, 20-22]. A previous Australian study also identified obesity as a risk factor of acquiring a disability [23]. The possible reason could be defined by low physical activity and metabolism deformity among the children who face health problems due to obesity [22, 24].

The children who use emergency services after birth, such as the services of ventilation in the intensive care unit, have a greater risk of living with disabilities in childhood. This agreement equates to an extant study that reported a significant association between ventilation utilisation and health complications [25]. The probable causes might be for difficulties and inconsistencies in perinatal events as this situation increases various health hazards [26]. Emergency care provides instant remedies; however, listed reasons create further medical issues among children, which are hard to deal with and have long term consequences.

Our study did not find evidence that gestational age has a statistically significant influence on children's medical condition. However, some retrospective cohort studies have identified it as a contributing factor of disability [9, 27]. Therefore, a further largescale investigation is required to examine the disparities across the studies through a systematic review.

Our study reveals risk factors of children's medical condition or disability that might contribute to inventing conservative approaches for public and private organisations to control the children's medical conditions or disabilities in Australia. First, screening programs based on nutritional and physical activity measurement for children could be planned to tackle the obesity epidemic. For example, each child could receive a diet chart and physical activity schedule considering their body mass index (BMI) through science-based intervention. According to the Australian Health and Wellbeing Strategic Framework 2017 to 2026, these proposed strategies create awareness about disease burden and provide knowledge about the necessity of maintaining a healthy lifestyle [28]. Second, accessible medical interventions are needed for pregnant women that promote understanding of pregnancyrelated hazards and health checkup advantages. It might help women to have increased awareness of their health status during the gestation period, increasing the possibility of delivering healthy infants. Third, different health strategies for male children might be designed to provide special attention since birth to lessen disease severity.

This study adds further insights in the current literature. This is the first study identifying the association between infant and child health characteristics with any medical condition or disability among Australian children. Additionally, the study considers 15 years of follow-up data from a large, nationally representative children's birth cohort in Australia. To escape bias, 'any medical condition or disability' is constructed to mean all possible diseases that occurred in childhood because the variability nature of measurement is observed across the studies [29]. Further, a wide range of infant and child health characteristics is included in this cohort study after considering the effect of maternal and child health related problems.

This study also has some limitations that should be acknowledged. First, examining the causal relationship is not possible due to the unbalanced longitudinal data. Therefore, future study is needed to identify the underlying association by considering the cause and generalizing the association for external settings in Australia. Second, the self-reported nature of BMI and chronic conditions might lead to reporting bias in the study. Third, disparities among the statistics have been found as non-participants make sample sizes unequal in the waves.

\section{Conclusion}

The current study assessed from a contemporary birth cohort of Australian children that low birthweight, receiving emergency hospital services just after birth, being male and being obese during childhood up to the age of 15 years are associated with increased hazard of having any medical condition or disability. These findings suggest that infants with low birth weight, children who have accessed hospital emergency services and children with obesity need further healthcare monitoring support from both private and public providers to improve the health and wellbeing of Australian children.

\section{Abbreviations}

HR: Hazard Ratio

LSAC: Longitudinal Study of Australian Children 
ICU: Intensive Care Unit

BMI: Body Mass Index

\section{Declarations}

\section{Acknowledgements}

This paper uses the data from Wave 1 to Wave 8 of the Longitudinal Study of Australian Children (LSAC). The authors thank the Australian Institute of Family Studies for providing the LSAC data. The authors also thank Dr Barbara Harmes and Dr Gail M Ormsby for proofreading the manuscript before submission.

\section{Authors' contributions}

KA was the principal investigator, designed the study, conducted the data analysis, and drafted the manuscript. SAK and NJS critically reviewed the manuscript and assisted with the final editing and writing of the manuscript. RK and EK contributed to the study design and development and editing the manuscript. The authors followed the STROBE guidelines for writing the manuscript. All authors read and approved the final manuscript.

\section{Funding}

This research did not receive any specific grant from funding agencies in the public, commercial, or not-for-profit sectors.

\section{Competing interests}

The authors declare that they have no known competing financial interest or personal relationships that could have appeared to influence the work reported in this paper.

\section{Ethics approval}

The LSAC study was approved by the Australian Institute of Family Studies Ethics Committee. The de-identified unit record dataset was released to the current researchers at the University of Southern Queensland for the purposes of this doctoral research. To obtain this data, the authors completed and signed the Confidentiality Deed Poll and sent it to NCLD (ncldresearch@dss.gov.au) and ADA (ada@anu.edu.au). Therefore, datasets analysed and/or generated during the current study are subject to the signed confidentiality deed.

\section{Consent for publication}

Not applicable.

\section{Availability of data and material}

The data used for the study were collected from the Longitudinal Study of Australian Children Dataverse of National Centre for Longitudinal Data. Those interested in accessing this data should contact the Longitudinal Study of Australian Children Dataverse of National Centre for Longitudinal Data, Australia. There are some restrictions on the use of this data and the data application's approval is subject to a signed confidentiality deed.

\section{References}

1. Disability and Health Overview [https://www.cdc.gov/ncbddd/disabilityandhealth/disability.html]

2. Benefits of Physical Activity [https://www.cdc.gov/physicalactivity/basics/pa-health/index.htm]

3. World Health Organization: The global burden of disease: 2004 update. In. Geneva; 2008.

4. UNICEF: THE STATE OF THE WORLD'S CHILDREN 2006: EXCLUDED AND INVISIBLE. New York; 2006. 
5. Disability, Ageing and Carers, Australia: Summary of Findings [https://www.abs.gov.au/statistics/health/disability/disabilityageing-and-carers-australia-summary-findings/latest-release\#data-download]

6. Ahmad K, Kabir E, Keramat SA, Khanam R: Maternal health and health-related behaviours and their associations with child health: Evidence from an Australian birth cohort. PLoS One 2021, 16(9):e0257188.

7. Chen YC, Fan HY, Yang C, Lee YL: Early pubertal maturation and risk of childhood asthma: A Mendelian randomization and longitudinal study. Allergy 2020, 75(4):892-900.

8. Maïano C, Hue O, Morin AJ, Moullec G: Prevalence of overweight and obesity among children and adolescents with intellectual disabilities: a systematic review and meta-analysis. Obes Rev 2016, 17(7):599-611.

9. Schendel D, Bhasin TK: Birth weight and gestational age characteristics of children with autism, including a comparison with other developmental disabilities. Pediatrics 2008, 121(6):1155-1164.

10. Schieve LA, Tian LH, Rankin K, Kogan MD, Yeargin-Allsopp M, Visser S, Rosenberg D: Population impact of preterm birth and low birth weight on developmental disabilities in US children. Annals of epidemiology 2016, 26(4):267-274.

11. Zhong Y, Wang J, Nicholas S: Gender, childhood and adult socioeconomic inequalities in functional disability among Chinese older adults. International journal for equity in health 2017, 16(1):1-11.

12. Langridge AT, Glasson EJ, Nassar N, Jacoby P, Pennell C, Hagan R, Bourke J, Leonard H, Stanley FJ: Maternal conditions and perinatal characteristics associated with autism spectrum disorder and intellectual disability. PloS one 2013, 8(1):e50963.

13. Williams K, Helmer M, Duncan G, Peat J, Mellis C: Perinatal and maternal risk factors for autism spectrum disorders in New South Wales, Australia. Child: care, health and development 2008, 34(2):249-256.

14. Claessen H, Arndt V, Drath C, Brenner H: Overweight, obesity and risk of work disability: a cohort study of construction workers in Germany. Occup Environ Med 2009, 66(6):402-409.

15. Corona LP, Alexandre TD, Duarte YA, Lebrao ML: Abdominal obesity as a risk factor for disability in Brazilian older adults. Public Health Nutr 2017, 20(6):1046-1053.

16. Zubrick S, Williams A, Silburn S, Vimpani G: Indicators of Social and Family Functioning. Department of Family and Community Services. Commonwealth of Australia: Canberra 2000.

17. Hack M, Taylor HG, Drotar D, Schluchter M, Cartar L, Andreias L, Wilson-Costello D, Klein N: Chronic conditions, functional limitations, and special health care needs of school-aged children born with extremely low-birth-weight in the 1990s. Jama 2005, 294(3):318-325.

18. Eaton WW, Mortensen PB, Thomsen PH, Frydenberg M: Obstetric complications and risk for severe psychopathology in childhood. Journal of autism and developmental disorders 2001, 31(3):279-285.

19. Cutland CL, Lackritz EM, Mallett-Moore T, Bardají A, Chandrasekaran R, Lahariya C, Nisar MI, Tapia MD, Pathirana J, Kochhar S: Low birth weight: Case definition \& guidelines for data collection, analysis, and presentation of maternal immunization safety data. Vaccine 2017, 35(48Part A):6492.

20. Ells LJ, Lang R, Shield JP, Wilkinson J, Lidstone J, Coulton S, Summerbell C: Obesity and disability-a short review. Obesity reviews 2006, 7(4):341-345.

21. Krause S, Ware R, McPherson L, Lennox N, O'Callaghan M: Obesity in adolescents with intellectual disability: Prevalence and associated characteristics. Obesity research \& clinical practice 2016, 10(5):520-530.

22. Lin JD, Yen CF, Li CW, Wu JL: Patterns of obesity among children and adolescents with intellectual disabilities in Taiwan. Journal of Applied Research in Intellectual Disabilities 2005, 18(2):123-129.

23. Keramat SA, Alam K, Sathi NJ, Gow J, Biddle SJH, Al-Hanawi MK: Self-reported disability and its association with obesity and physical activity in Australian adults: Results from a longitudinal study. SSM Popul Health 2021, 14:100765.

24. Donini LM, Merola G, Poggiogalle E, Lubrano C, Gnessi L, Mariani S, Migliaccio S, Lenzi A: Disability, physical inactivity, and impaired health-related quality of life are not different in metabolically healthy vs. unhealthy obese subjects. Nutrients 2016, 8(12):759.

25. Clini E, Ambrosino N: Early physiotherapy in the respiratory intensive care unit. Respir Med 2005, 99(9):1096-1104.

26. Barton SK, Tolcos M, Miller SL, Roehr CC, Schmolzer GM, Davis PG, Moss TJ, LaRosa DA, Hooper SB, Polglase GR: Unraveling the Links Between the Initiation of Ventilation and Brain Injury in Preterm Infants. Front Pediatr 2015, 3:97. 
27. Heuvelman H, Abel K, Wicks S, Gardner R, Johnstone E, Lee B, Magnusson C, Dalman C, Rai D: Gestational age at birth and risk of intellectual disability without a common genetic cause. European journal of epidemiology 2018, 33(7):667-678.

28. Australian Health Ministers' Advisory Council: National Strategic Framework for Chronic Conditions. In. Canberra: Australian Government; 2017.

29. World Health Organization: World Report on Disability. In. Malta; 2011.

Figures

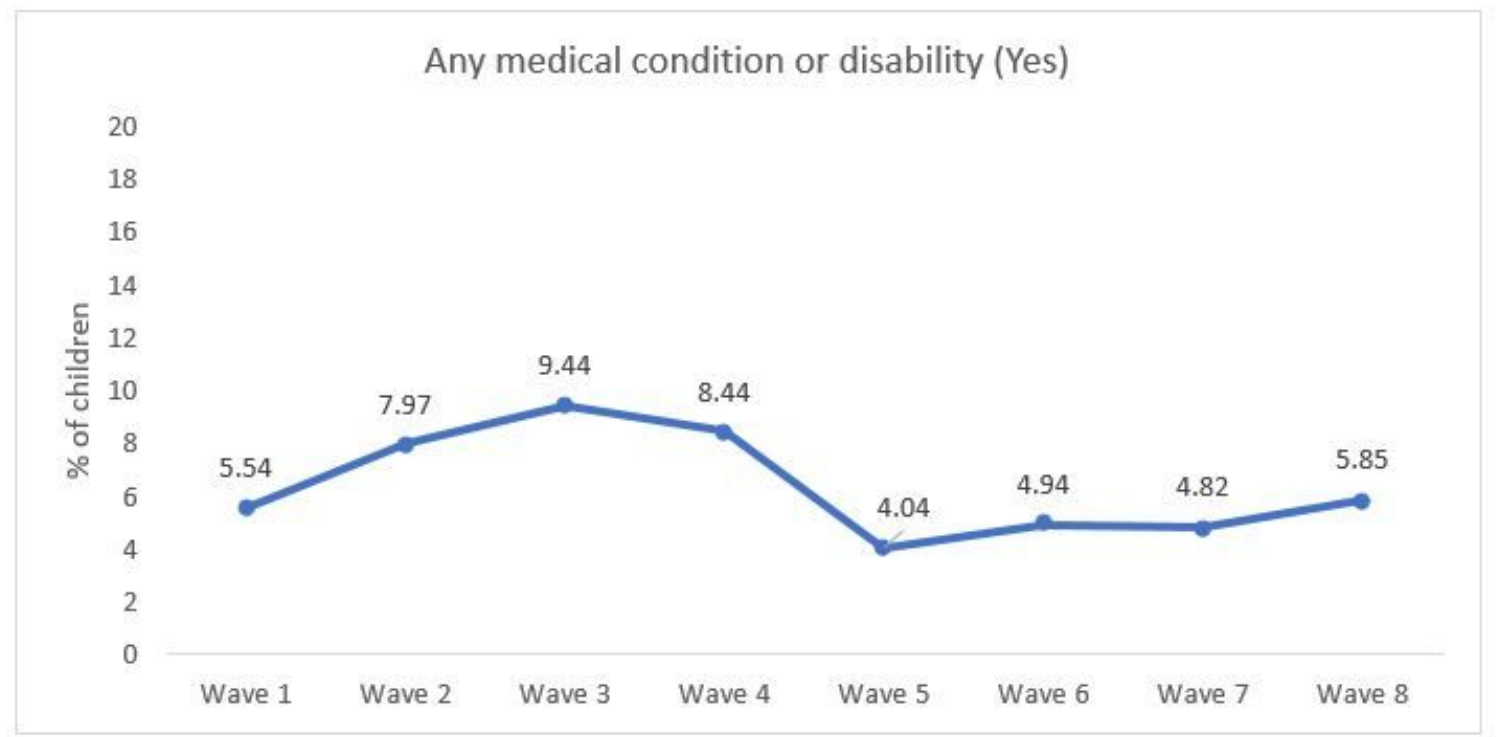

\section{Figure 1}

Prevalence of any medical condition or disability health hazard among Australian children across the waves, 2004-2018 


\section{Random-effects Weibull Proportional Hazard Regression}
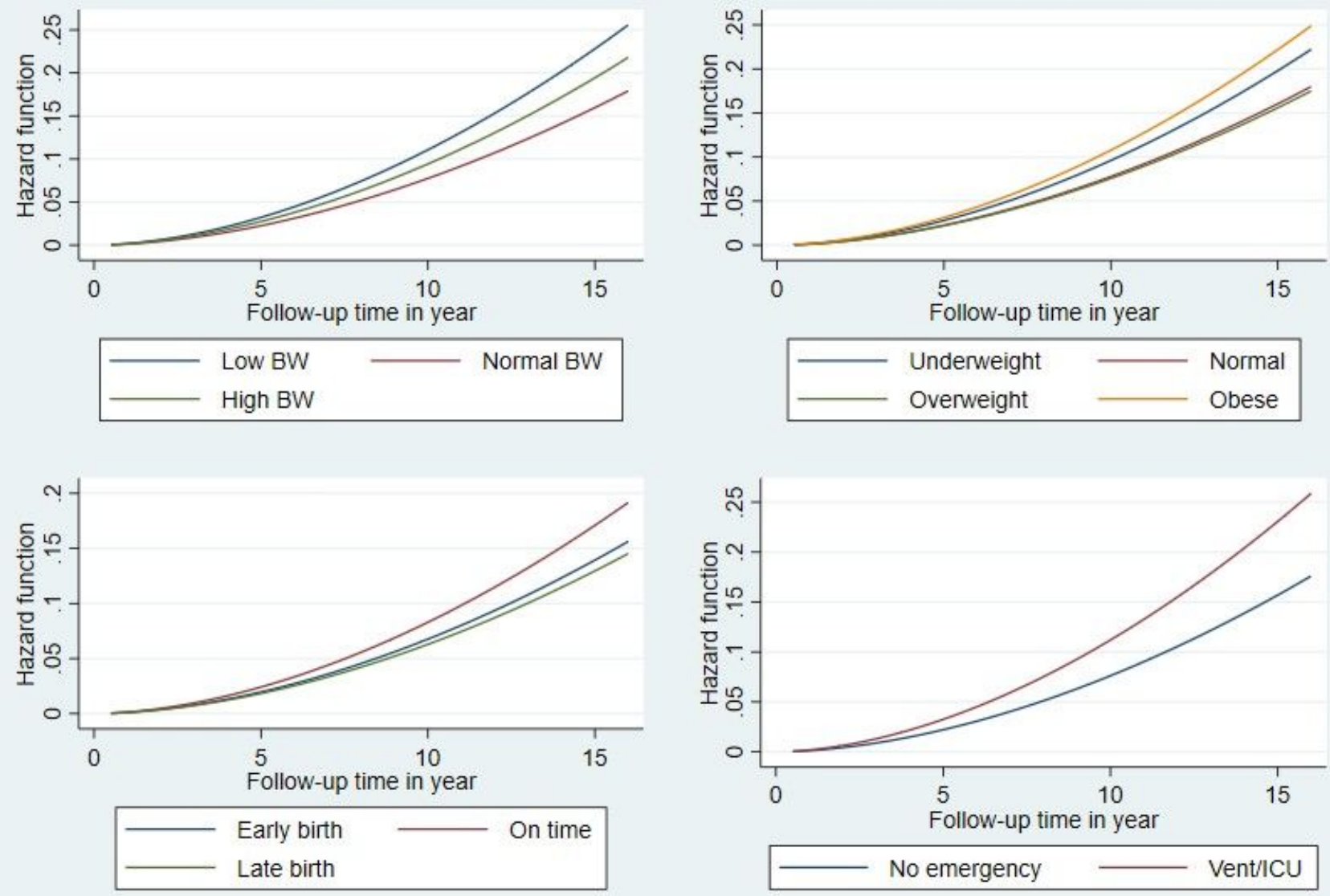

\section{Figure 2}

Smooth curves of proportional hazard regression on hazard functions of children across the years by birthweight, obesity status, gestational age and after birth emergency services use of the children 

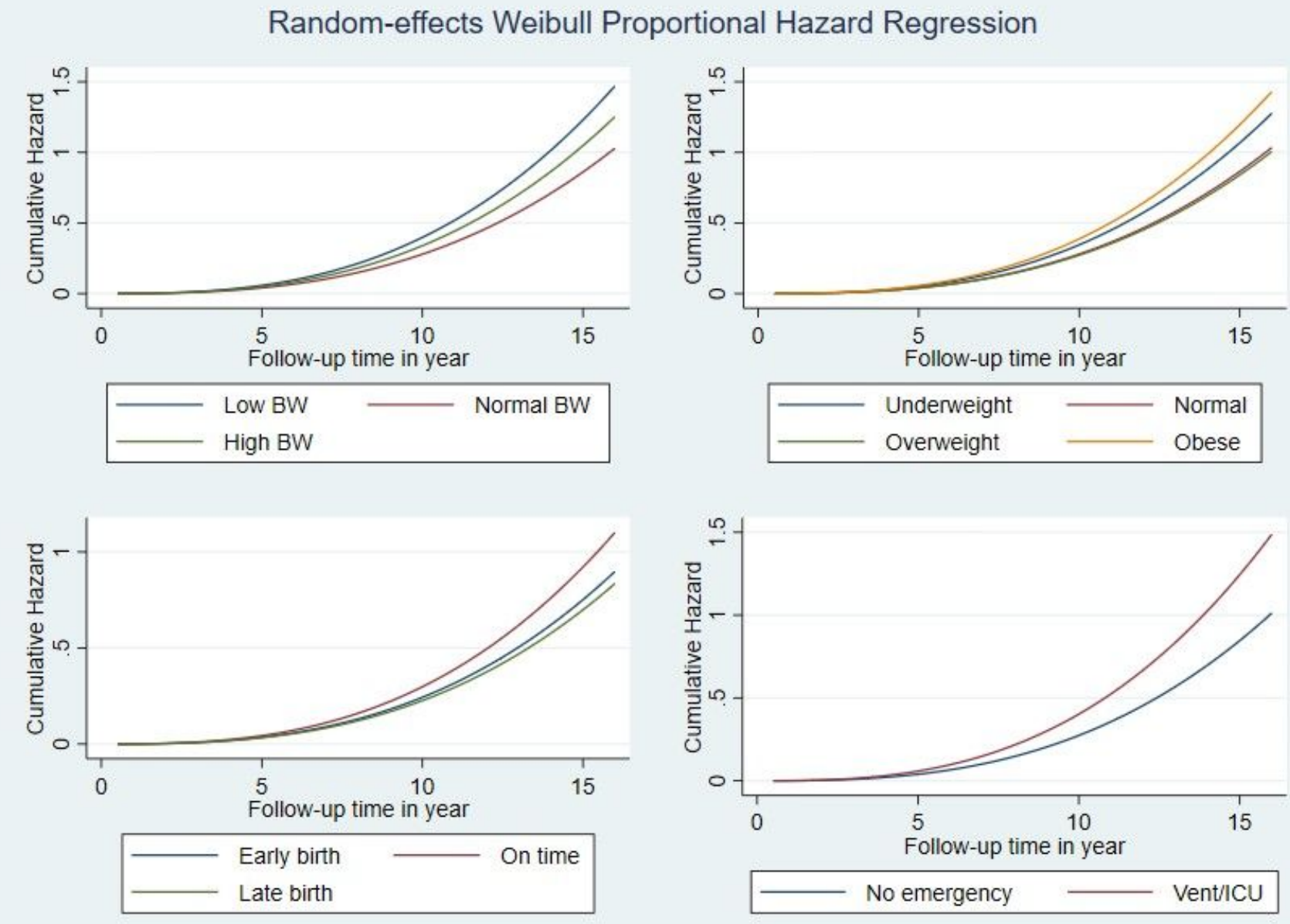

\section{Figure 3}

Smooth curves of proportional hazard regression on cumulative hazard functions of children across the years by birthweight, obesity status, gestational age and after birth emergency services use of the children 

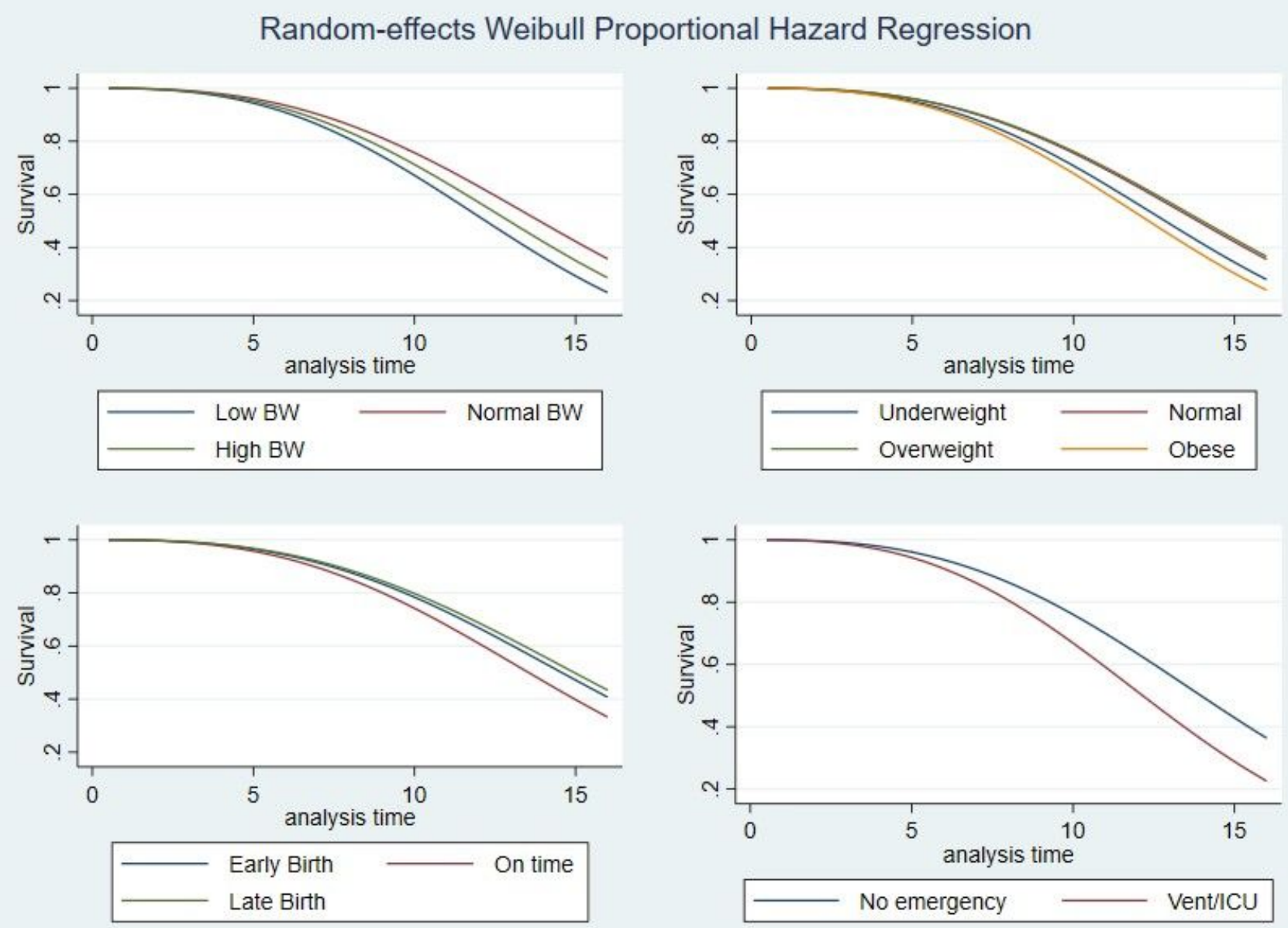

\section{Figure 4}

Smooth curves of proportional hazard regression on survival functions of children across the years by birthweight, obesity status, gestational age and after birth emergency services use of the children 